Universidad de Lima

Facultad de Comunicación

Carrera de Comunicación

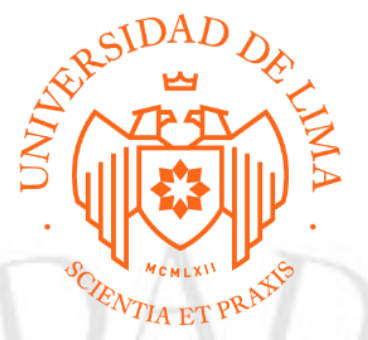

\title{
CAMPAÑA DE LANZAMIENTO DE SAPHI, CONCENTRADO DE CHICHA MORADA
}

Trabajo de Suficiencia Profesional para optar el Título Profesional de Licenciado en

Comunicación

\section{Erwin Alfredo Solis Sparrow}

Código 20141284

$$
\begin{gathered}
\text { Lima - Perú } \\
\text { Mayo de } 2019
\end{gathered}
$$




\section{CAMPAÑA DE LANZAMIENTO DE SAPHI, CONCENTRADO DE CHICHA MORADA}




\section{ÍNDICE}

RESUMEN ....................................................... Pág. 5

INTRODUCCIÓN ...................................................... Pág. 6

I. ANÁLISIS DEL SECTOR .............................................. Pág. 7

I.I Situación actual ................................................ Pág. 7

I.2 Competencia .................................................. Pág. 8

II. OBJETIVOS DE LA CAMPAÑA ..................................... Pág. 12

II.I Objetivos de Marketing .......................................... Pág. 12

II.I.I Estrategias de Marketing ................................... Pág. 12

II.II Objetivos de Comunicación.................................... Pág. 12

II.I.II Estrategias de Comunicación ................................... Pág. 12

III. PÚBLICO OBJETIVO ............................................. Pág 13

III.I Descripción del público objetivo .................................. Pág. 13

III.II Percepciones del público objetivo ............................. Pág. 14

III.III Buyer persona ................................................ Pág. 14

IV. DESCRIPCIÓN DEL PRODUCTO .................................... Pág. 15

IV.I Producto .......................................................... Pág. 15

IV.II Promesa .......................................................... Pág. 15

IV.III Soporte ...................................................... Pág. 15

IV.IV Ventaja competitiva ............................................... Pág. 15

IV. V Precio .................................................. Pág. 15

IV. VI Distribución ............................................... Pág. 15

V. IDENTIDAD DE MARCA ....................................... Pág. 16

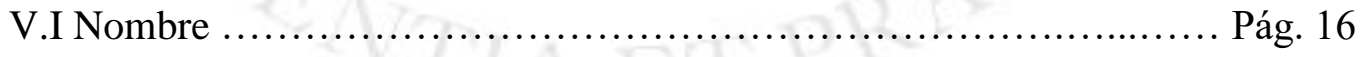

V.II Posicionamiento ................................................. Pág. 16

V.III Personalidad .................................................. Pág. 16

V. IV Propuesta de valor .............................................. Pág. 16

V.V Logo ............................................................. Pág. 17

V. VI Packaging ...................................................... Pág. 18

VI. ESTRATEGIA CREATIVA ........................................ Pág. 20

VI. I Insights ......................................................... Pág. 20

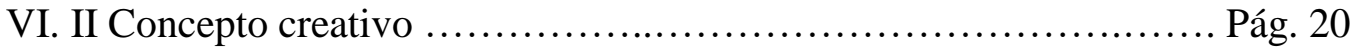


VII. ESTRATEGIA DE MEDIOS

Pág. 21

VII.I Presupuesto Pág. 21

VII.II Televisión Pág. 23

VII. III Radio Pág. 22

VII. IV OOH Pág. 24

VII. V POP Pág. 23

VII. VI DIGITAL

Pág. 26

VIII. CONCLUSIONES

Pág. 30

IX. RECOMENDACIONES Pág. 31

$X$. REFERENCIAS Pág. 32

XI. ANEXOS Pág. 34 


\section{RESUMEN}

El presente trabajo desarrolla una campaña de lanzamiento para una marca de concentrado de chicha morada en el mercado peruano. El público objetivo resalta el sabor original de esta bebida y relacionan lo natural con lo saludable.

Ante este insight, se propone comunicar a Saphi como el sabor natural de siempre, con la receta original que solo tiene la chicha morada hecha en casa.

Sobre este concepto, se desarrolló un plan de medios integral para lograr el reconocimiento y posicionamiento de la marca tanto de manera offline como digital. 


\section{INTRODUCCIÓN}

El presente trabajo plantea una campaña de lanzamiento para una marca de concentrado de chicha morada que desea ingresar al mercado.

El proyecto tuvo como requerimientos la propuesta de nombre, diseño de empaque, una campaña de comunicación integral, material para punto de venta y degustaciones. El presupuesto asignado fue de US \$500,000.

Se inició con la investigación de las percepciones del público objetivo respecto a la chicha morada para definir insights y definir un concepto de campaña. El nombre se eligió en base a la historia y referencias del producto.

Posteriormente, se definieron los medios y las piezas de comunicación para comunicar las propiedades del producto. 


\section{ANÁLISIS DEL SECTOR}

\section{I.I Antecedentes}

En la actualidad, millones de personas a nivel mundial están cambiando sus hábitos alimenticios y practican más deportes para cuidar su salud. Alimentos como las gaseosas, las galletas y las frituras están perdiendo popularidad, provocando que las grandes empresas tengan que adaptarse a esta tendencia saludable.

Los consumidores de hoy "son aquellos que están cada vez más conscientes de lo que ellos mismos y sus familias comen. Son los que tratan de encontrar un balance en la alimentación, procuran que esta sea más sana y son más cuidadosos con lo que adquieren, leyendo las etiquetas". (Oie, 2019)

Los peruanos buscan consumir frutas, verduras, beber agua y leer la información en las etiquetas de los envasados. A su vez, los fabricantes de productos con contenido graso o azucarado ya ofrecen alternativas más saludables. Es así que el $54 \%$ de hogares peruanos se considera "saludable" o "muy saludable". (Kantar Worldpanel, 2019)

Para fortalecer esta tendencia, se promulgó una ley de Promoción de la Alimentación Saludable para Niños, Niñas y Adolescentes que dispone el uso de un sistema de etiquetado de advertencia en los productos procesados.

Todos los alimentos industrializados que se vendan en el Perú deberán llevar, a partir del 17 de junio de 2019, octógonos de advertencia que informen que su contenido excede los parámetros establecidos por la ciencia para el sodio, azúcar, grasas saturadas o grasas trans. (El Comercio, 2019).

Por otro lado, según Gestión (2019), el consumo de bebidas saludables representa el 14\% del mercado en Perú y la tendencia es que aumente debido a esta medida y por el nuevo comportamiento del consumidor. 
Ante esta situación, las bebidas naturales de nuestro país pueden destacar por su sabor, composición e historia, tal como es el caso de la chicha morada, bebida de sabor nacional, la cual es una muestra viviente de nuestra tradición ancestral. Es elaborada con maíz morado como ingrediente principal junto con membrillo, piña, limón, canela y canela. Es una de las bebidas más populares de los peruanos.

\section{I.II Competencia}

Naturale

Naturale es una empresa peruana con más de quince años en el mercado que produce y comercializa alimentos y bebidas. Su producto principal es el concentrado de chicha morada y se comercializa en dos presentaciones: bolsa y botella. Ambas versiones están hechas a base de Maíz morado, Membrillo, Piña, Manzana, Canela y Clavo de olor. (Naturale, 2019)

La bolsa de plástico contiene dos litros de esencia y rinde entre ocho y diez litros de chicha morada, mientras que la botella de un litro entre cuatro y cinco litros de bebida. La marca está presente en supermercados, bodegas, practi-tiendas, restaurantes y empresas a nivel nacional a través de refresqueras y máquinas expendedoras.

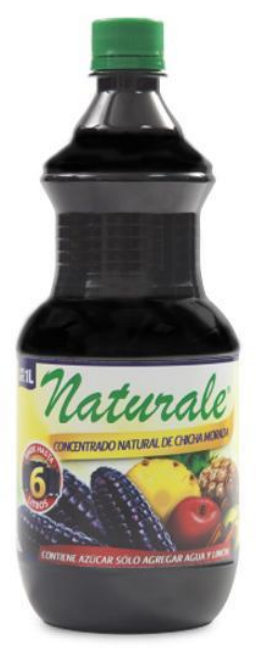




\section{a. Soy Frutta}

Corporación Merati S.A.C. es una empresa peruana dedicada a la producción de alimentos y bebidas a base de extractos naturales y pulpas de fruta, bajo las marcas "Wayu's" y "Soy Frutta" elaborados bajo los mejores estándares de calidad, una infraestructura adecuada, estricto control de los procesos y con el apoyo de nuestros colaboradores. (Corporación Merati, 2019)

El producto se comercializa en tres presentaciones: bolsa de 2 litros (rinde 12 litros), 1 litro (rinde 6 litros) y $500 \mathrm{ml}$. (rinde 3 litros).

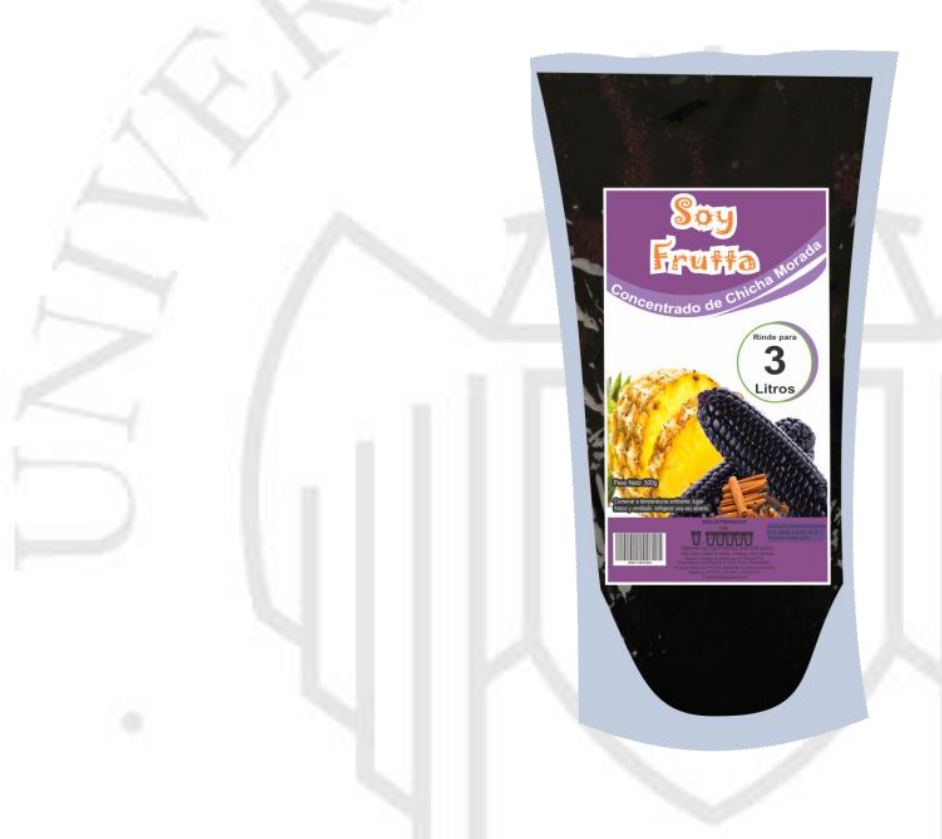

b. TokeFrut

KarFrut es una empresa del sector agroindustrial que funciona en Lima desde 2012. Se encargan de procesar y entregar pulpas de fruta que son insumos clave para la industria de alimentos. Los principales atributos que comunican de su marca TokeFrut es que es práctico, saludable y rentable. El sachet de $2 \mathrm{~kg}$. rinde 10 litros de bebida. 


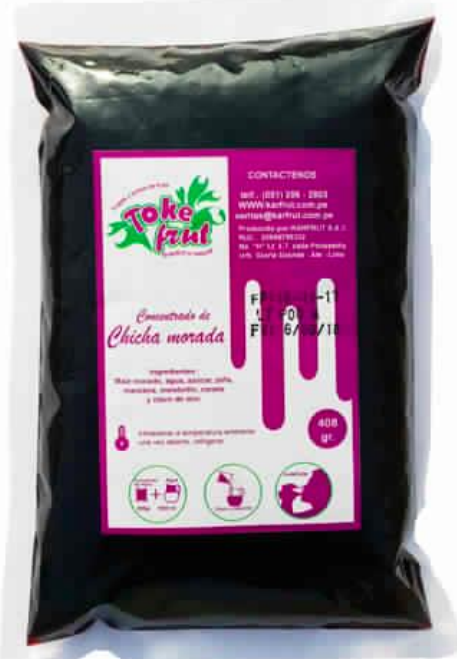

Por otro lado, también se pueden considerar como competencias las siguientes marcas:

\section{c. Zuko}

Zuko es una de las bebidas instantáneas en polvo más populares de nuestro país. Es un producto de la Compañía Nacional de Chocolates de Perú S.A y cuenta con gran experiencia en la producción y comercialización de productos de consumo masivo.

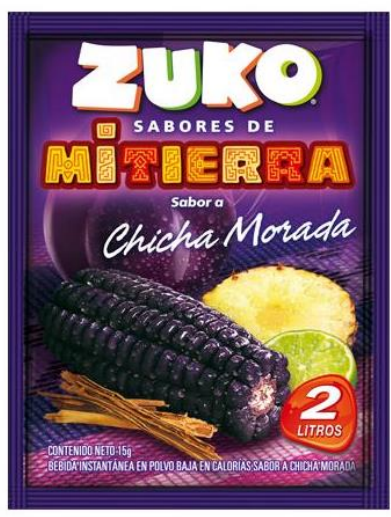




\section{d. Negrita}

Alicorp es la empresa dueña de Negrita, la popular chicha morada en polvo, que ha acompañado a los peruanos en los últimos años. Su eslogan "Sabe lo que te gusta" es reconocible por el público gracias a su buena campaña de comunicación. El producto se comercializa a nivel nacional en bodegas, mercados y supermercados.

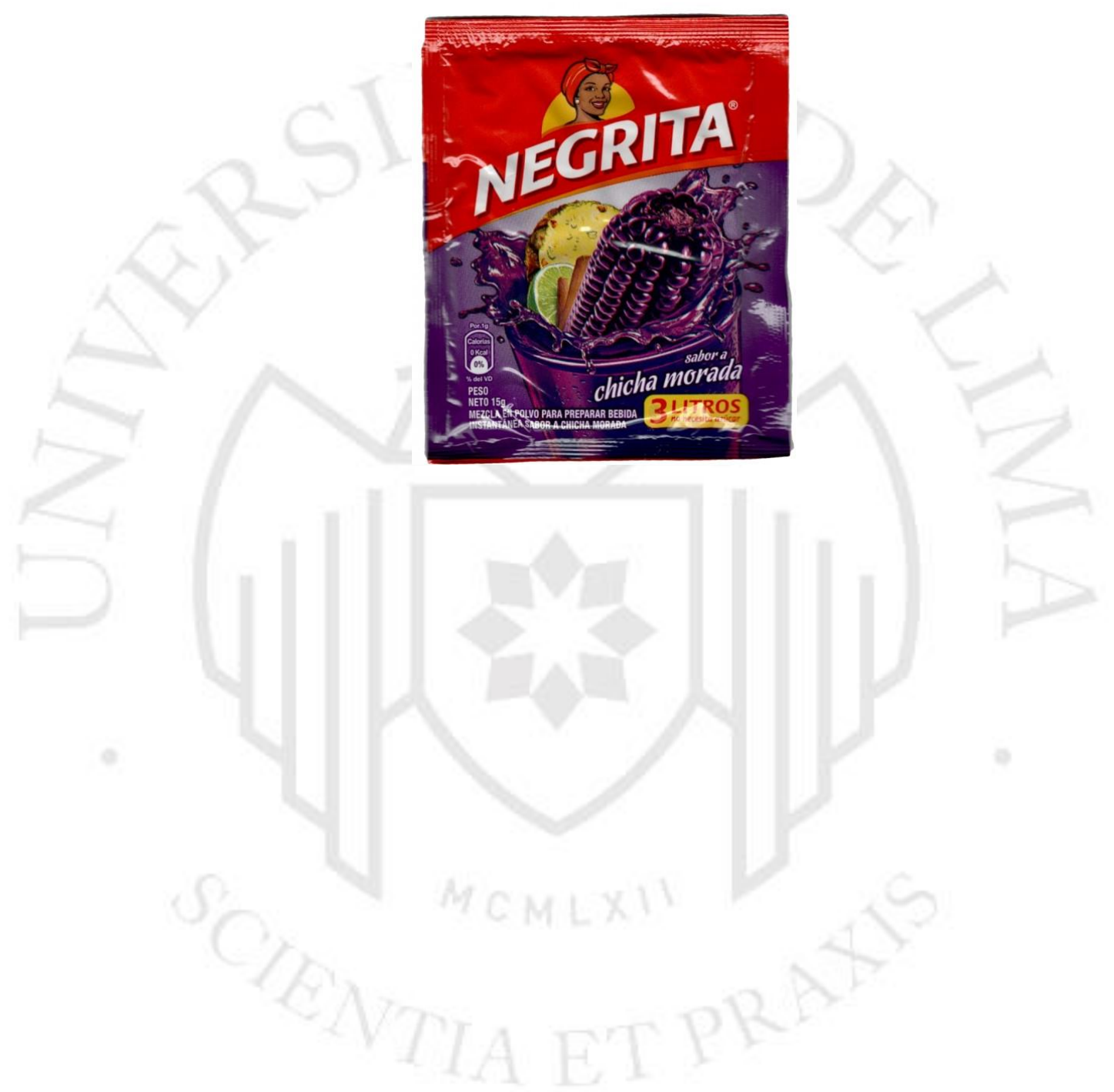




\section{OBJETIVOS DE LA CAMPAÑA}

II.I Objetivos de Marketing

- Generar conocimiento y recordación de marca por parte del público objetivo en el lapso de 6 meses.

- Alcanzar el liderazgo en el rubro de concentrados de chicha morada, en el mercado peruano en el lapso de un año.

\section{II.I.I Estrategias de Marketing}

El plan de medios integral permitirá lograr una gran exposición de la marca Saphi. El público objetivo crea el mensaje dado para conseguir que la marca sea recordada y reconocida en el punto de compra. La estrategia de medios va a permitir que Saphi se posicione en el top of mind de las amas de casa del NSE A, B y C como el concentrado de chicha morada hecho con ingredientes naturales y sin preservantes.

\section{II.I Objetivos de Comunicación}

- Informar sobre el lanzamiento de Saphi, destacando sus ingredientes naturales y que está hecho con la receta tradicional de casa.

- Dar a conocer los beneficios del consumo de la chicha morada.

- Informar sobre los puntos de venta de Saphi.

\section{II.II Estrategias de Comunicación}

Se debe reforzar la idea que Saphi es un producto $100 \%$ natural, tiene la misma receta de la chicha morada tradicional y tiene beneficios nutricionales. La publicidad en Facebook, Instagram, y en el resto de la web ayudarán a recordar estas propiedades. 


\section{PÚBLICO OBJETIVO}

III.I Descripción del público objetivo

El público objetivo son mujeres amas de casa entre 30 a 45 años de los NSE A, B y C. Según IPSOS (2018), nueve de cada diez amas de casa peruanas son madres de familia y tienen entre 1 y 3 hijos. Se dedican al hogar y también tienen un empleo, principalmente las del NSE C.

Según Arellano Marketing (2019), en su tiempo libre, además de descansar, les agrada hacer manualidades, escuchar música y ver televisión. Disfrutan yendo a casa de familiares, cines, parques y centros comerciales. Les gusta practicar deporte y pasear.

Cuando tienen tiempo libre, se preocupan principalmente por los niños, a ver televisión y a los quehaceres del hogar. Al momento de comprar, el consumo es una actividad entretenida, divertida y muy emocionante y les interesan los productos que ofrezcan reducir el tiempo y esfuerzo en las labores del hogar y que eviten hacerlas sentir solamente "amas de casa" (Arellano Marketing, 2019)

Cuando tienen tiempo libre lo dedican principalmente a los niños, a ver televisión y a los quehaceres del hogar. La televisión sigue siendo el medio masivo más usado para seguir promociones e Internet es el más consumido para informarse de los beneficios. En cuanto a la radio, las amas de casa del NSE C escuchan más radio que los NSE A y B. Las emisoras principales son Radio Corazón y Ritmo Romántica. Tres de cada cinco amas de casa son digitales (Facebook e Instagram) y el tipo de video que ven son musicales, películas y noticias (IPSOS, 2018)

Las amas de casa relacionan lo natural con lo saludable y lo toman en cuenta en la alimentación de sus hijos. Ellas valoran el sabor real de la chicha morada con la receta tradicional de casa, pero no tienen tiempo de prepararla y consideran que es un procedimiento tedioso. No conocen los valores nutritivos de la chicha morada, pero sí prefieren para sus hijos un producto que sea natural en comparación con la artificial que viene en polvo. 
III.II Percepciones del público objetivo

Se realizaron 100 encuestas a personas que son parte del público objetivo y se obtuvieron las siguientes conclusiones:

- El sabor es la característica que más destacan de la chicha morada.

- La mayoría de las amas de casa toman chicha morada una vez a la semana.

- Casi todas las amas de casa suelen consumir chicha morada en el almuerzo.

- La casa es el principal lugar donde se consume la chicha morada.

- El largo tiempo de preparación es el aspecto que menos les gusta de preparar chicha morada.

\section{III.III Buyer persona}

Carolina tiene 34 años, estudió Administración de Empresas en la UPC y acaba de ascender a Jefe de Recursos Humanos en una empresa que comercializa cosméticos. Ella es madre de una niña de seis años y junto a su esposo viven en un departamento en Surco.

De lunes a viernes, Carolina se levanta temprano para prepararle el desayuno a su hija, ponerle el uniforme y llevarla en el auto al colegio. Luego, trabaja de 08:00 a.m. a 05:00 p.m. A las 02:00 p.m. la abuela recoge a su nieta para cuidarla hasta que Carolina salga del trabajo, durante esas horas solo se comunican por celular. En las noches hacen juntas las tareas y juegan un rato.

Los sábados y domingos son días especiales porque los tres miembros de la familia pueden despertar sin apuro y realizar diversas actividades juntos, en especial almorzar en casa. Es el momento más importante del día porque pueden conversar, reír y compartir.

Carolina se preocupa mucho por el bienestar de toda su familia y siempre quiere darles lo mejor. En sus ratos libres navega por redes sociales y sigue páginas que da consejos de cómo ser mejor mamá, una alimentación saludable y arreglar cada espacio de su hogar. Ella intenta seguir cada tip que encuentra, pero trabajar y ser mamá ocupa mucho tiempo en su día. 


\section{DESCRIPCIÓN DEL PRODUCTO}

\section{IV.I Producto}

Saphi es una marca de concentrado de chicha morada cuyo principal diferencial es que está compuesta por ingredientes $100 \%$ naturales de la receta tradicional casera. Asimismo, tiene beneficios para la salud.

\section{IV.II Promesa}

Ponemos al alcance de las familias peruanas la deliciosa chicha morada con el sabor de siempre a través de una presentación súper sencilla de preparar y que es $100 \%$ natural.

\section{IV.III Soporte}

Los ingredientes son los mismos de la receta tradicional de la chicha morada con ingredientes naturales que no han sido modificados, así como que tampoco tiene preservantes ni colorantes.

IV.IV Ventaja competitiva

Saphi es el único concentrado de chicha morada con ingredientes $100 \%$ naturales que no tiene preservantes ni colorantes. Es sencillo de preparar y tiene beneficios nutricionales.

\section{IV.V Precio}

La presentación de $500 \mathrm{ml}$. se vendería a S/ 6.00.

\section{IV.VI Distribución}

Se venderá en autoservicios de Lima y grandes ciudades y también en las principales bodegas. Se presentarán visicooleres (exhibidores refrigerados) para los principales autoservicios. 


\section{IDENTIDAD DE MARCA}

\section{V.I Nombre}

Para definir el nombre de la marca, se consideró una de las características más importantes de la Chicha Morada: ser una bebida tradicional que ha acompañado a las familias peruanas de generación en generación y que ha estado presente en cada momento de nuestra historia.

Saphi es una palabra quechua que significa "raíz", y tal como la Chicha Morada, es el origen de cada uno de los momentos familiares donde se comparten distintas tradiciones de casa. Es el refresco que ha formado parte de nuestra historia y de nuestras raíces, ya que el maíz morado ha sido encontrado desde la época pre inca. Por último, es un nombre que fortalece la esencia natural del maíz morado, ya que es un producto que proviene de las raíces de nuestros campos.

\section{V.II Posicionamiento}

Saphi es la verdadera Chicha Morada elaborada con la receta tradicional casera, basada en la concentración del maíz morado con una combinación de frutas y especias naturales. Es una bebida saludable para la familia porque no contiene saborizantes ni preservantes.

\section{V.III Personalidad}

Saphi se preocupa por estar presente en la vida de las personas que más quiere y lo demuestra en cada pequeño gesto que realiza. Si bien es moderna, tiene ese corazón tradicional por dentro que busca generar contacto con los demás a través de largas conversaciones, compartiendo risas y sueños para inspirarlos a ser mejores. Por otro lado, Saphi se preocupa por estar bien tanto por fuera como por dentro, a la vez que también ayuda al resto a hacerlo.

V.IV Propuesta de valor:

Saphi es la verdadera chicha morada hecha con la receta tradicional, es fácil de preparar y es $100 \%$ natural. 


\section{V.VI Logo}

El logo de Saphi debe transmitir la modernidad que caracteriza al público objetivo y la simplicidad con la que se puede preparar la chicha morada con este producto. El color elegido fue el morado (\#3d1a30) para asociar fácilmente a la bebida tradicional. Por otro lado, se utilizó la tipografía Auro Bold por ser Sans Serif, con muchas curvas para dar una imagen sencilla y contemporánea.

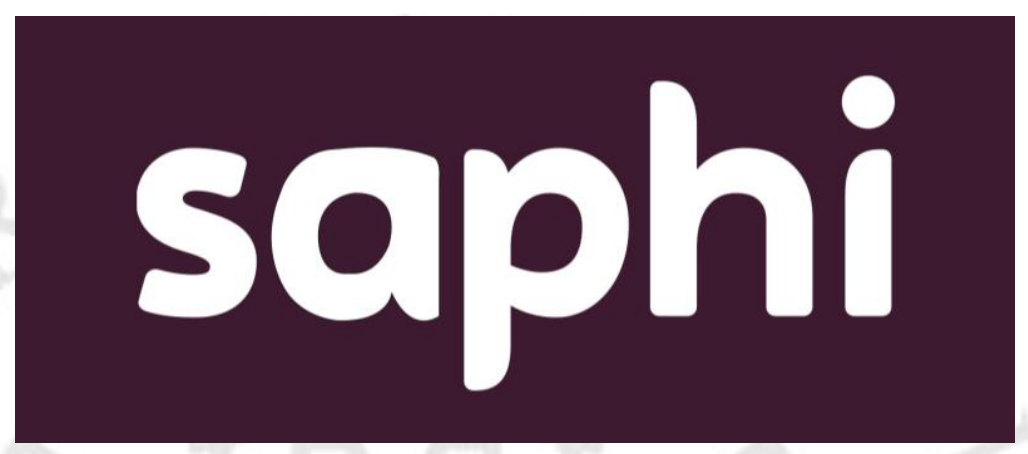

Versión en blanco y negro:
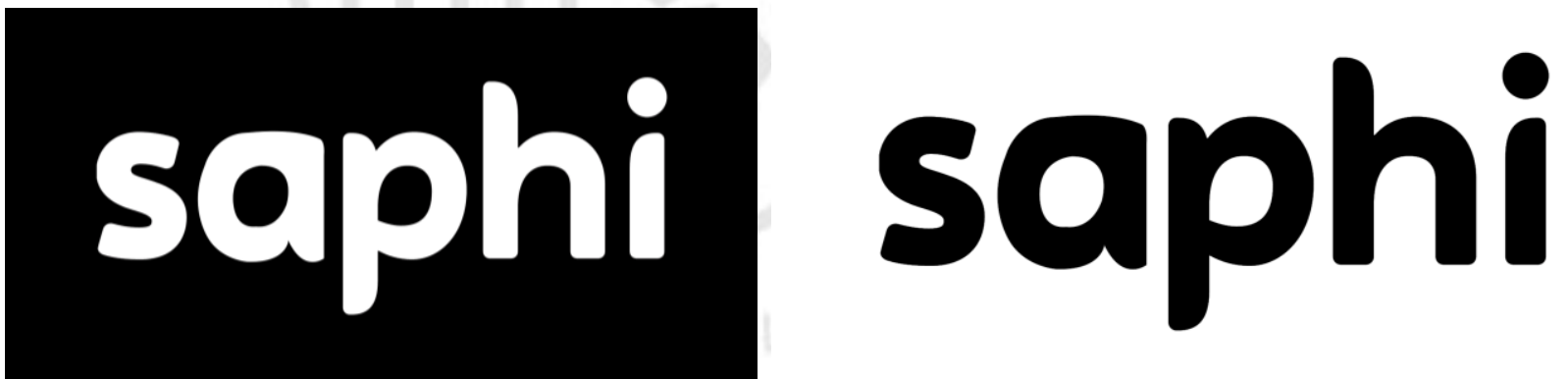


\section{V.VII Packaging}

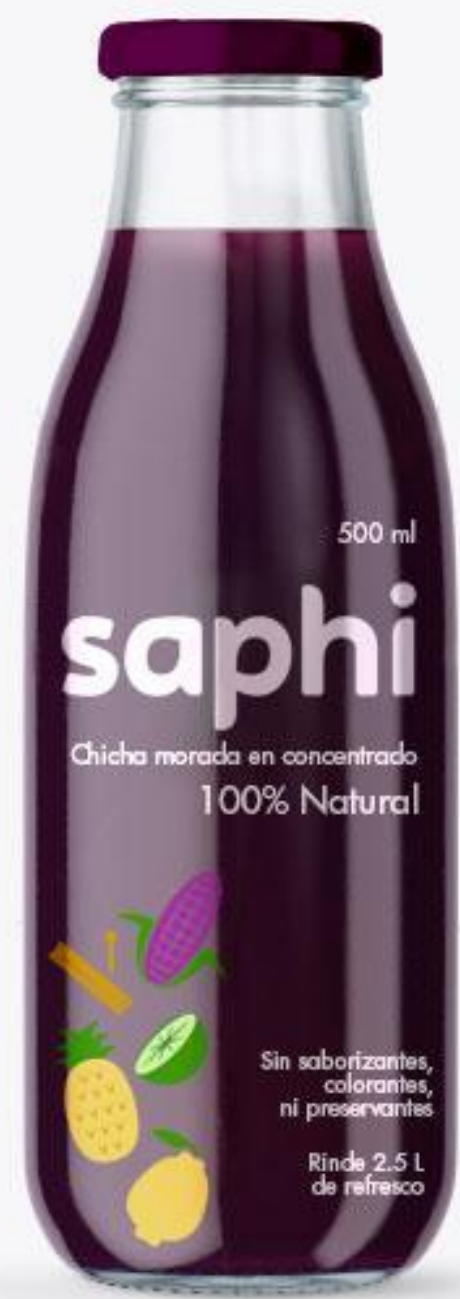

El diseño de la etiqueta tiene como característica principal el tener de fondo transparente para que el concentrado de color morado sea el protagonista. Esta contiene el logo, la cantidad de concentrado que viene en la presentación y cuánto rinde, las ventajas diferenciales (100\% natural, sin saborizantes, colorantes ni preservantes), la información nutricional, el procedimiento para preparar, los ingredientes, información de la empresa, redes sociales de la marca y el código de barras para adquirir el producto. 


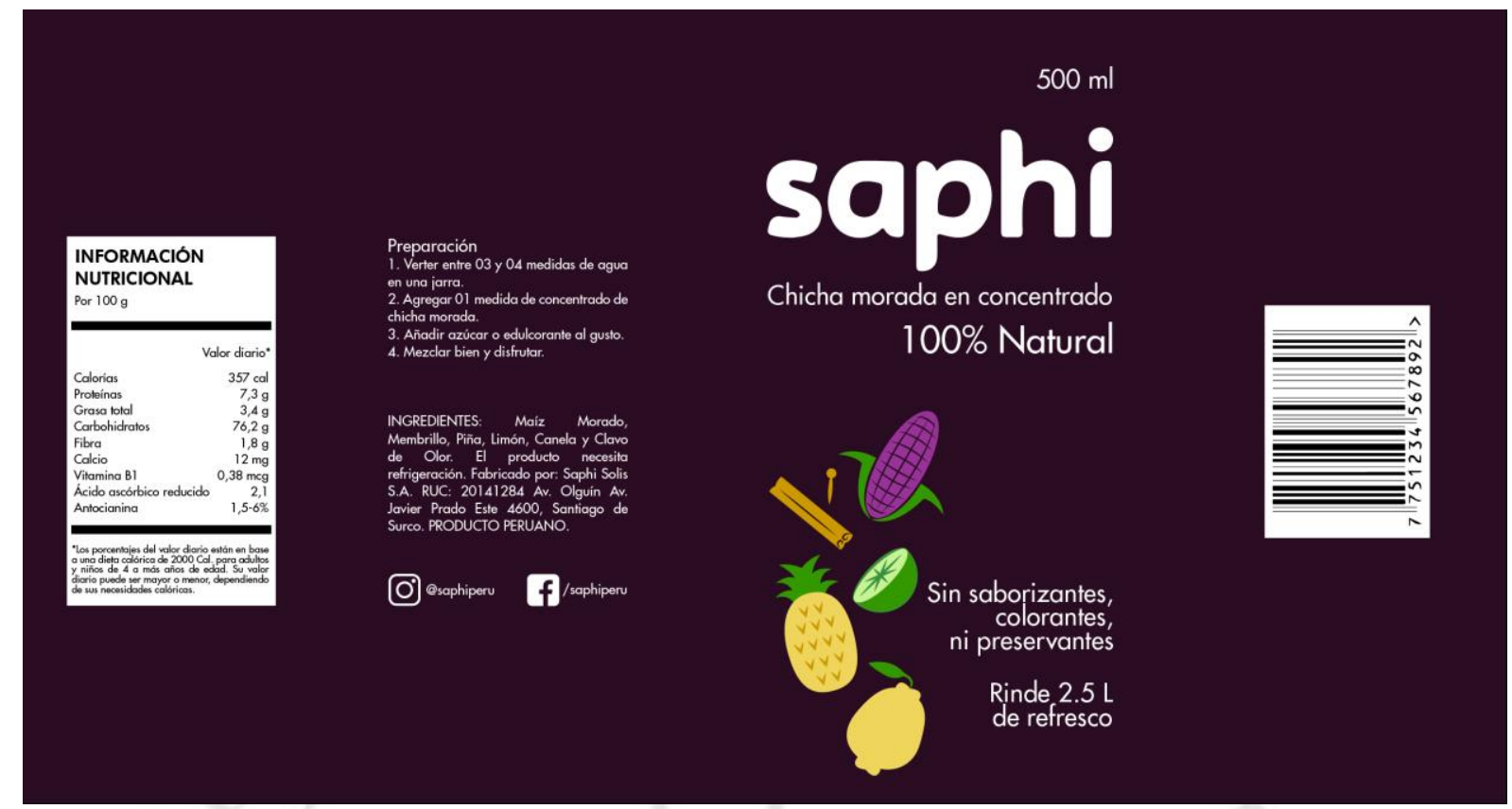

La botella está hecha de vidrio con el tamaño regular de $216 \mathrm{~mm}$ de alto y $70 \mathrm{~mm}$ de ancho para que contenga $500 \mathrm{ml}$ y así sea práctica de adquirir en los supermercados. 


\section{ESTRATEGIA CREATIVA}

\section{VI.I Insights}

Las amas de casa recuerdan con mucho cariño cuando eran niñas y cómo sus madres les llamaban para almorzar. Ellas veían que a sus mamás se les hacía complicado preparar chicha morada ya que tomaba bastante tiempo. Asimismo, creen que no hay nadie que prepare mejor la chicha morada como mamá sabe hacerlo y que no hay receta como la de mamá. Hogar es cualquier lugar en donde esté mamá.

Por otro lado, la chicha morada no es cualquier bebida, no es una limonada que se prepara en cualquier momento, es perfecta para fechas especiales. La chicha morada solo es rica en casa.

Por otro lado, las amas de casa de hoy buscan generar contacto con su familia y fortalecer la cercanía. La casa es su lugar favorito, lo consideran su templo y creen que no hay nada como almorzar ahí y pasar la tarde descansando.

\section{VI.II Concepto creativo}

El concepto creativo para la campaña de lanzamiento de Saphi es "El sabor natural de siempre" que busca reforzar las cualidades de la Chicha Morada. En primer lugar, esta bebida tiene un sabor único y es una de las más consumidas en nuestro país. Las personas no suelen consumirla fuera de casa porque consideran que no es natural, está hecha de sobre o no la preparan bien.

En segundo lugar, Saphi es un producto natural porque está hecho con ingredientes no modificados, así como no contiene colorantes ni preservantes. Los ingredientes de la chicha morada tienen muchos beneficios en la salud de las personas.

Por último, es una bebida que ha estado siempre en la vida de millones de familias peruanas a lo largo de nuestra historia, nos ha acompañado en cada celebración, reunión familiar, almuerzo y fiesta infantil. La chicha morada es pura tradición y sigue formando parte de los mejores momentos del Perú. 


\section{ESTRATEGIA DE MEDIOS}

VII.I Presupuesto

La presente campaña tiene un presupuesto de $\$ 500,000$ y fue distribuido de la siguiente manera:

\begin{tabular}{|l|l|lr|}
\hline & En Dólares & \multicolumn{2}{|l|}{ Tipo de cambio } \\
\hline & USD & & 3.30 \\
\hline
\end{tabular}

\begin{tabular}{|c|c|c|c|}
\hline ATL & En Dólares & Tipc & \\
\hline Desarrollo de guion para spot tv y radio & $9,000.00$ & S/ & 3.30 \\
\hline $\begin{array}{l}\text { Producción, realización y edición de } \\
\text { spot tv }\end{array}$ & $\begin{array}{l}\text { USD } \\
35,000.00\end{array}$ & & 3.30 \\
\hline $\begin{array}{l}\text { Producción, realización y edición de } \\
\text { radio }\end{array}$ & USD $\quad 6,000.00$ & S/ & 3.30 \\
\hline Pauta en tv nacional & $\begin{array}{l}\text { USD } \\
80,000.00 \\
\end{array}$ & & 3.30 \\
\hline Pauta en radio & $\begin{array}{l}\text { USD } \\
25,000.00\end{array}$ & S/ & 3.30 \\
\hline Paneles & $\begin{array}{l}\text { USD } \\
110,000.00\end{array}$ & S/ & 3.30 \\
\hline Jalavistas & USD $\quad 2,000.00$ & S/ & 3.30 \\
\hline Branding de visicoolers & USD $\quad 4,000.00$ & S/ & 3.30 \\
\hline Total & $\begin{array}{l}\text { USD } \\
271,000.00\end{array}$ & & \\
\hline
\end{tabular}

\begin{tabular}{|l|l|ll|}
\hline DIGITAL & & & \\
\hline & USD & S/ & 3.30 \\
\hline Pauta en Facebook & $84,200.00$ & & \\
Pauta en Instagram & USD & S/ & 3.30 \\
\hline & $40,000.00$ & \multicolumn{2}{|c|}{} \\
Pauta en Google (Display) & USD & S/ & 3.30 \\
\hline & $80,000.00$ & & \\
Total & USD & & \\
\hline
\end{tabular}




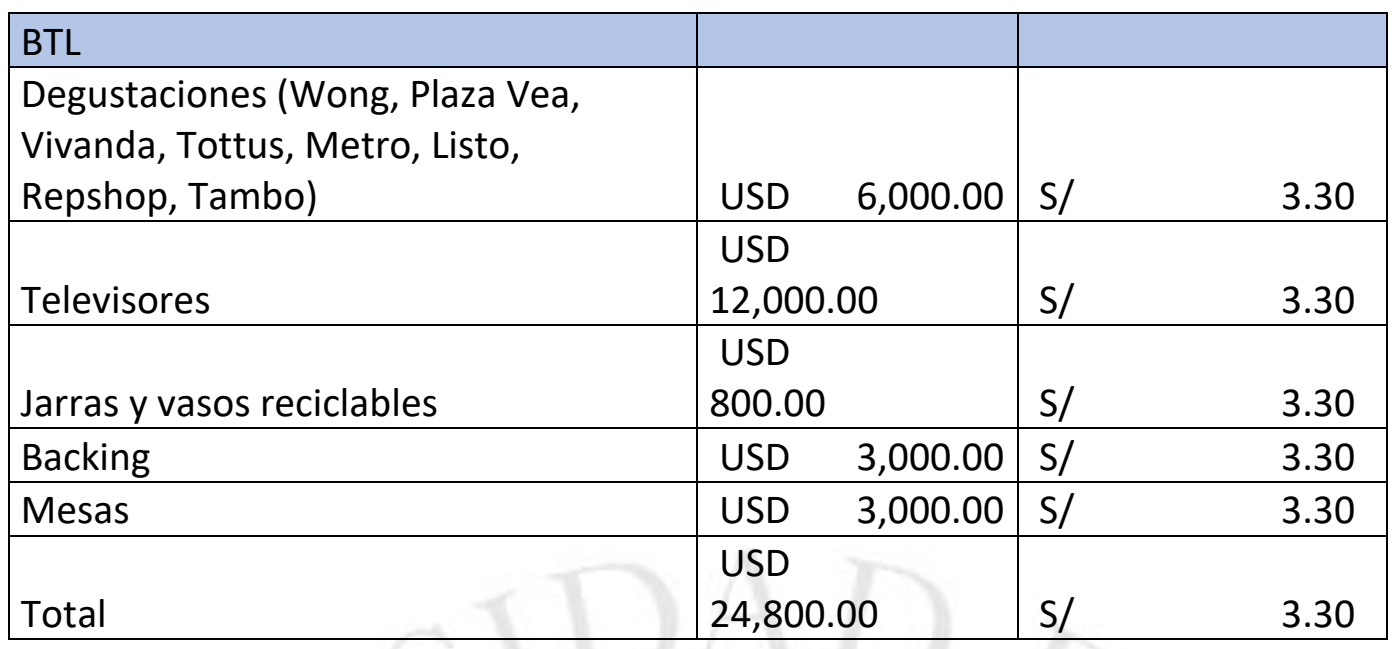

Plan de medios:

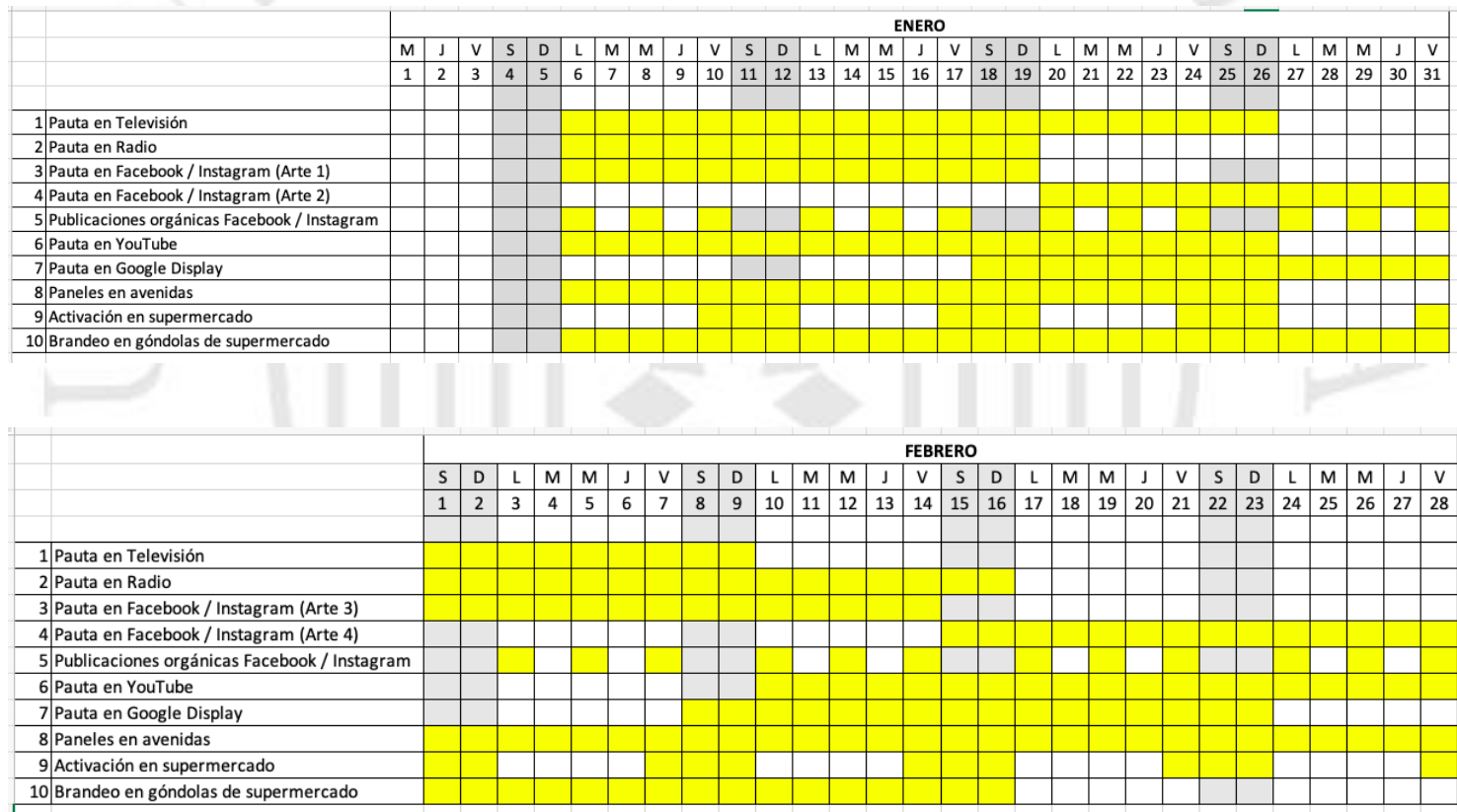

\begin{tabular}{|c|c|c|c|c|c|c|c|c|c|c|c|c|c|c|c|c|c|c|c|c|c|c|c|c|c|c|c|c|c|c|c|c|}
\hline & \multicolumn{32}{|c|}{ MARZO } \\
\hline & $\mathrm{D}$ & $\mathrm{L}$ & M & $\mathrm{M}$ & $\mathrm{J}$ & $\mathrm{v}$ & $\mathrm{s}$ & $\mathrm{D}$ & $\mathrm{L}$ & M & M & $\mathrm{J}$ & $\mathrm{v}$ & $s$ & $\mathrm{D}$ & $\mathrm{L}$ & $\mathrm{M}$ & $\mathrm{M}$ & 1 & $\mathrm{v}$ & $s$ & D & $\mathrm{L}$ & M & M & \begin{tabular}{l|l}
1 \\
\end{tabular} & $\mathrm{v}$ & & & $D$ & $\mathrm{~L}$ & $\mathrm{M}$ \\
\hline & 1 & 2 & 3 & 4 & 5 & 6 & 7 & 8 & 9 & 10 & 11 & 12 & 13 & 14 & 15 & 16 & 17 & 18 & 19 & 20 & 21 & 22 & 23 & \begin{tabular}{|l|l|}
324 & $r l$
\end{tabular} & 25 & \begin{tabular}{|l|l|l}
5 & 26 \\
\end{tabular} & \begin{tabular}{|l|l}
527 & $r a r b$ \\
\end{tabular} & \begin{tabular}{l|l}
7 & 2 \\
\end{tabular} & & 29 & 30 & 31 \\
\hline & & & & & & & & & & & & & & & & & & & & & & & & & & & & & & & & \\
\hline 3 Pauta en Facebook / Instagram (Arte 5) & & & & & & & & & & & & & & & & & & & & & & & & & & & & & & & & \\
\hline 4 Pauta en Facebook / Instagram (Arte 6) & & & & & & & & & & & & & & & & & & & & & & & & & & & & & & & & \\
\hline $\begin{array}{l}5 \\
\end{array}$ ublicaciones orgánicas Facebook / Instagram & & & & & & & & & & & & & & & & & & & & & & & & & & & & & & & & \\
\hline 6 Pauta en YouTube & & & & & & & & & & & & & & & & & & & & & & & & & & . & & & & & & \\
\hline \begin{tabular}{|l|l|}
7 Pauta en Google Display \\
\end{tabular} & & & & & & & & & & & & & & & & & & & & & & & & & & & & & & & & \\
\hline \begin{tabular}{|l|l|}
9 & Activación en supermercado \\
\end{tabular} & & & & & & & & & & & & & & & & & & & & & & & & & & & & & & & & \\
\hline 10 Brandeo en góndolas de supermercado & & & & & & & & & & & & & & & & & & & & & & & & & & & & & & & & \\
\hline
\end{tabular}




\section{VII.II Televisión}

La presencia en televisión para este público objetivo es importante, por lo que se invertirá en Latina, América TV y ATV, en especial en el horario de 07:00 a.m. - 10:00 a.m., 12:00 p.m. - 04:00 p.m. y 19:00 - 22:00 p.m.

Los programas que se transmiten en ese horario son los más vistos por nuestro público objetivo.

Concepto del spot: Se deben mostrar las situaciones en donde los chicos de hoy pasan su tiempo (juegos con realidad aumentada, selfies y filtros) pero cuando la mamá llama a comer, todos corren y se sientan en la mesa. La voz en off debe decir "Los años pasan y las costumbres cambian, pero lo único que nos une es el verdadero sabor de la chicha morada", seguido del packshot y el texto "El sabor natural de siempre".

\section{VII.III Radio}

El mismo concepto del comercial anterior debe ser difundido en radio. Las emisoras más importantes para las amas de casa son Ritmo Romántica, Radio Corazón y Oxígeno. La duración es de 30 segundos y serán programados en el horario de la mañana (07:00 a.m. - 10:00 a.m.) y en la noche (06:00 p.m. - 09:00 p.m.) 


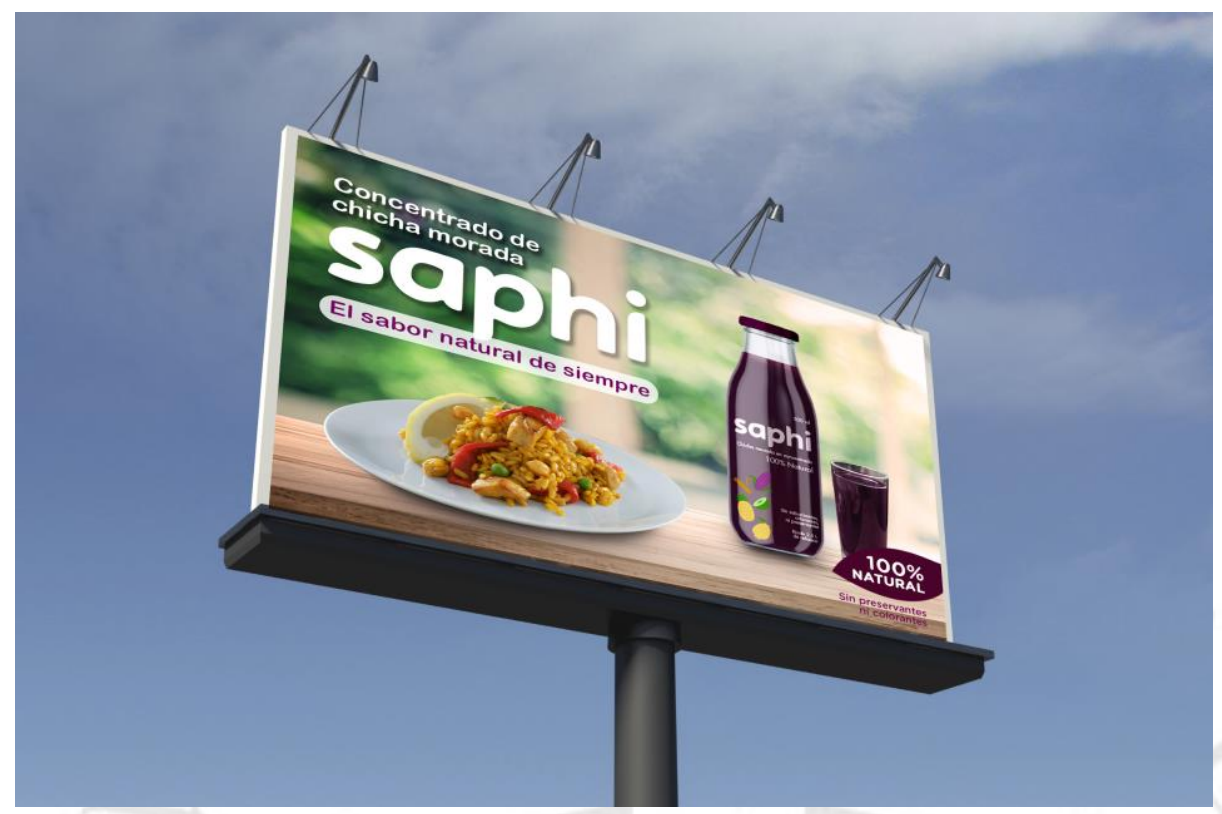

Se colocarán paneles publicitarios en puntos estratégicos de Lima ya que es importante tener presencia en las calles para lograr recordación de marca. Se colocarán en los distritos de Barranco, Surco, Miraflores, La Molina, San Isidro y San Borja.

\section{VII.V POP (Point of Purchase)}

Los visicoolers de los supermercados y bodegas que contengan nuestros productos serán brandeados con el logo de Saphi, junto con los ingredientes y los beneficios a los costados 


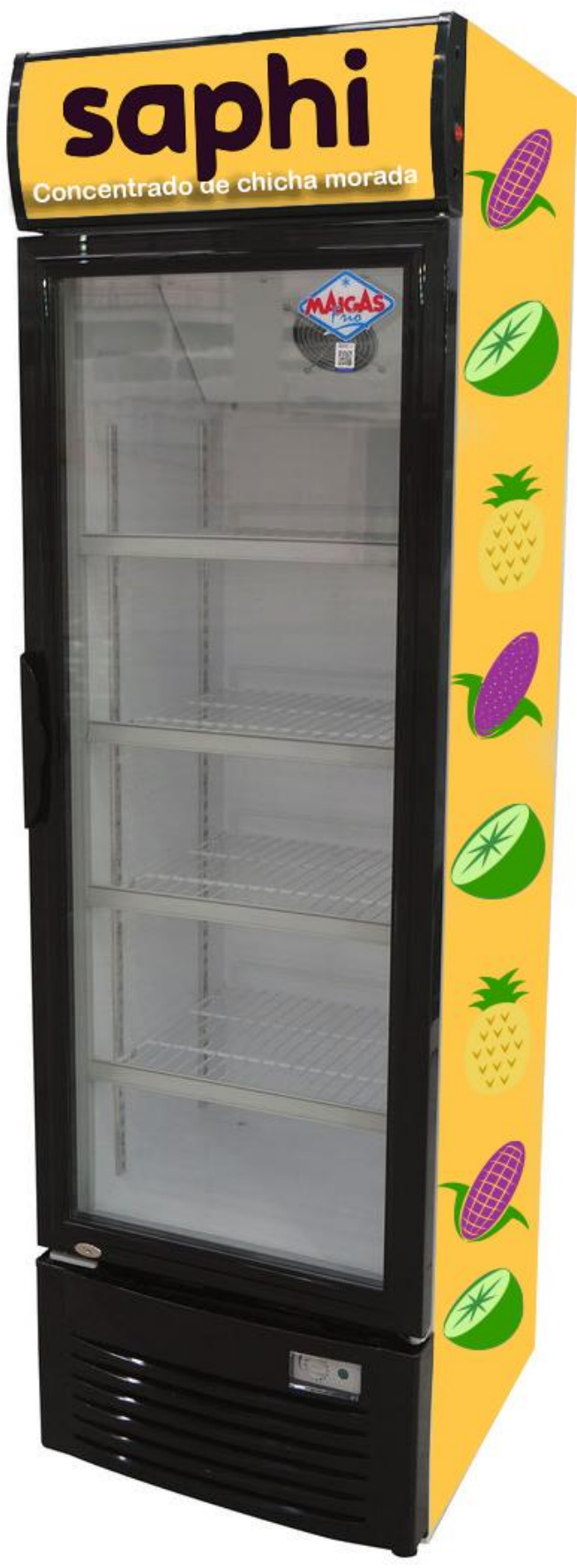

Por otro lado, en coordinación con los supermercados se colocarán jalavistas para que las botellas de Saphi resalten frente a la competencia, de forma circular, el nombre y la botella de tamaño grande para que llame más la atención. 


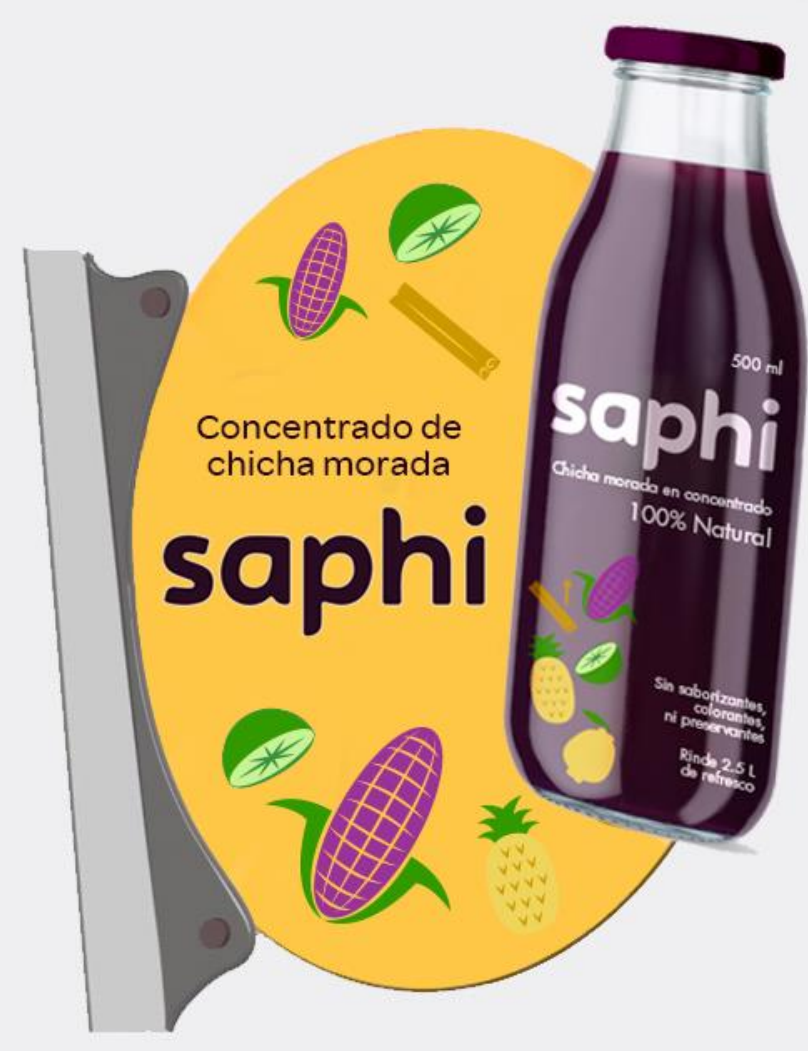

La degustación en el supermercado consiste en la presencia de una ama de casa (35 años) vestida con blusa (vestimenta de oficina) con el fondo de un campo de maíz, una mesa de comedor, dos pantallas de TV. en formato vertical. La temática consiste en que el ama de casa coloca los ingredientes detrás del televisor (mientras que la pantalla muestra cómo los ingredientes “mágicamente" se mezclan", el video se detiene, acerca su mano y retira una botella de Saphi como si fuera un acto de sorpresa. En ese momento abre la botella, lo vierte en una jarra de agua, se mezcla y hace degustar al público presente.

\section{VII.VI Digital}

- Facebook

La publicidad en Facebook estará segmentada a mujeres con hijos entre 30 a 45 años de las principales ciudades con intereses en familia, salud, vida sana, nutrición. Los textos de las publicaciones serán "Prueba Saphi, el concentrado de chicha morada con la receta tradicional", "Saphi es el único concentrado de chicha morada que no incluye 
preservantes ni colorantes. ¡Pruébala!” y "Dale a tu familia la mejor chicha con la receta casera."

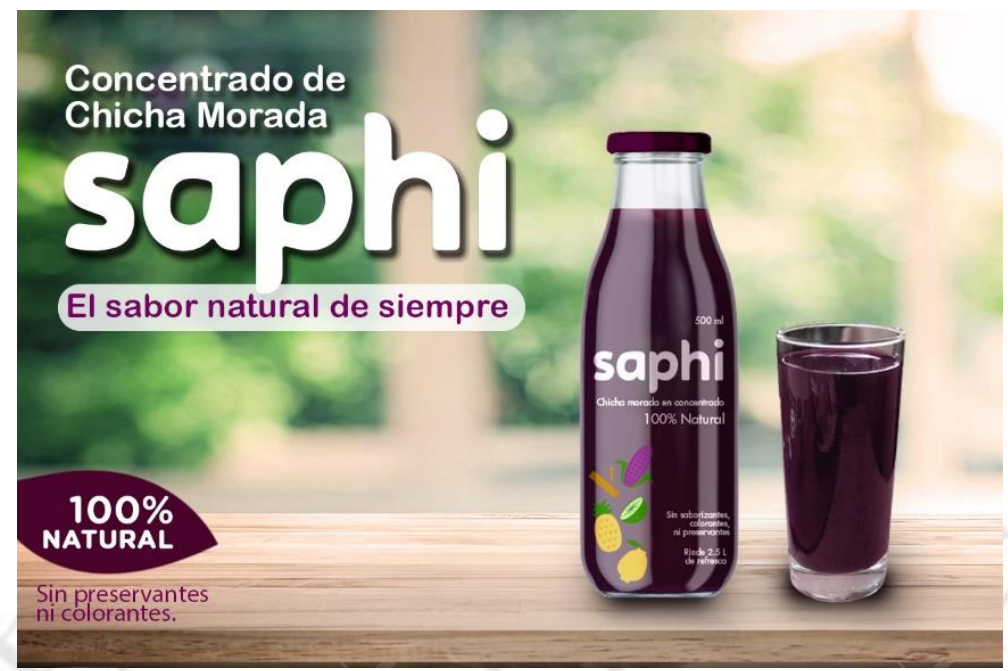

\section{- Instagram}

El público objetivo de la pauta será el mismo que en Facebook y aparecerá ajustado a formato story y post. Los intereses se comparten, pero aquí se incluirá el interés de comidas naturales, tipo de publicación popular en esta red.
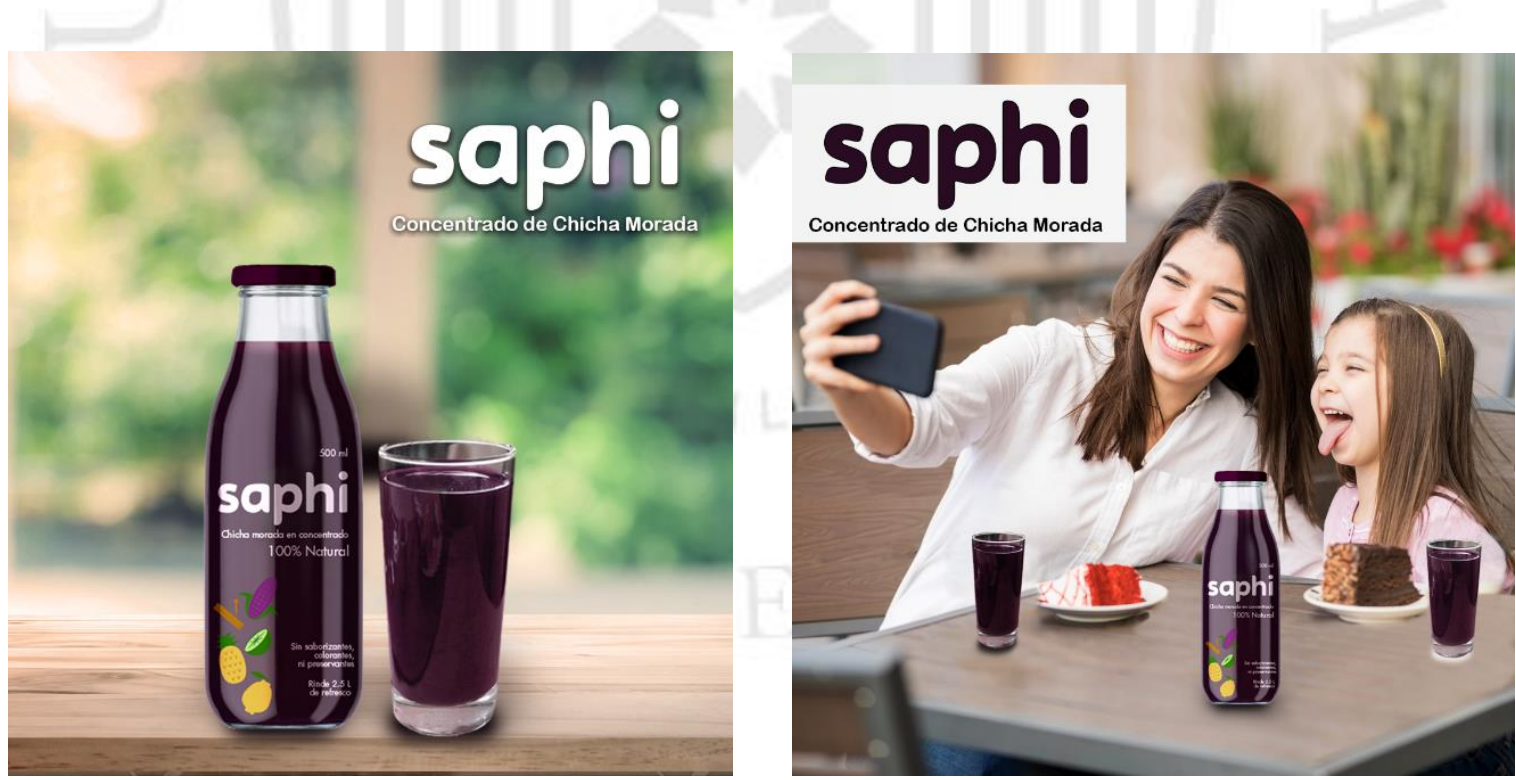
Sabor de siempre:
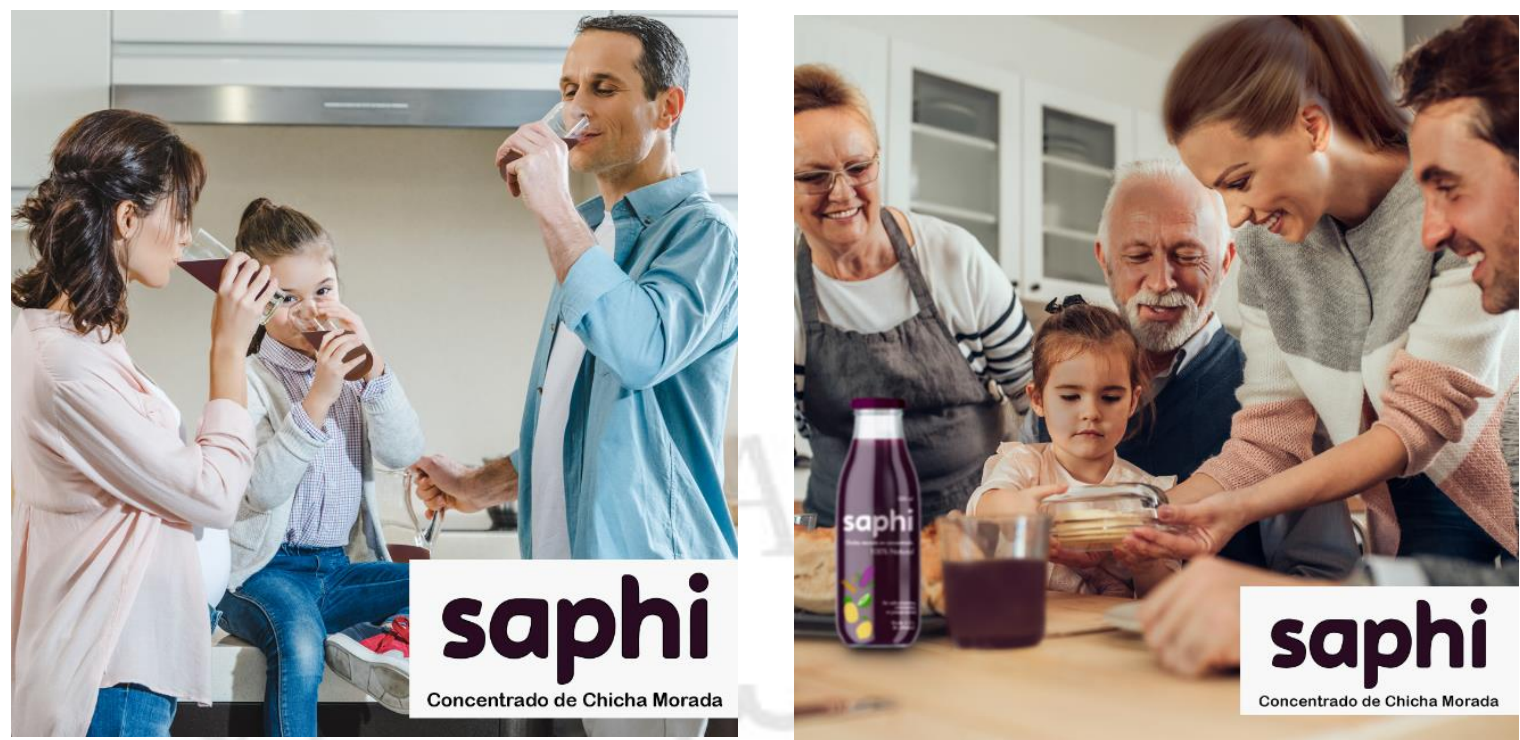

Beneficios nutricionales:
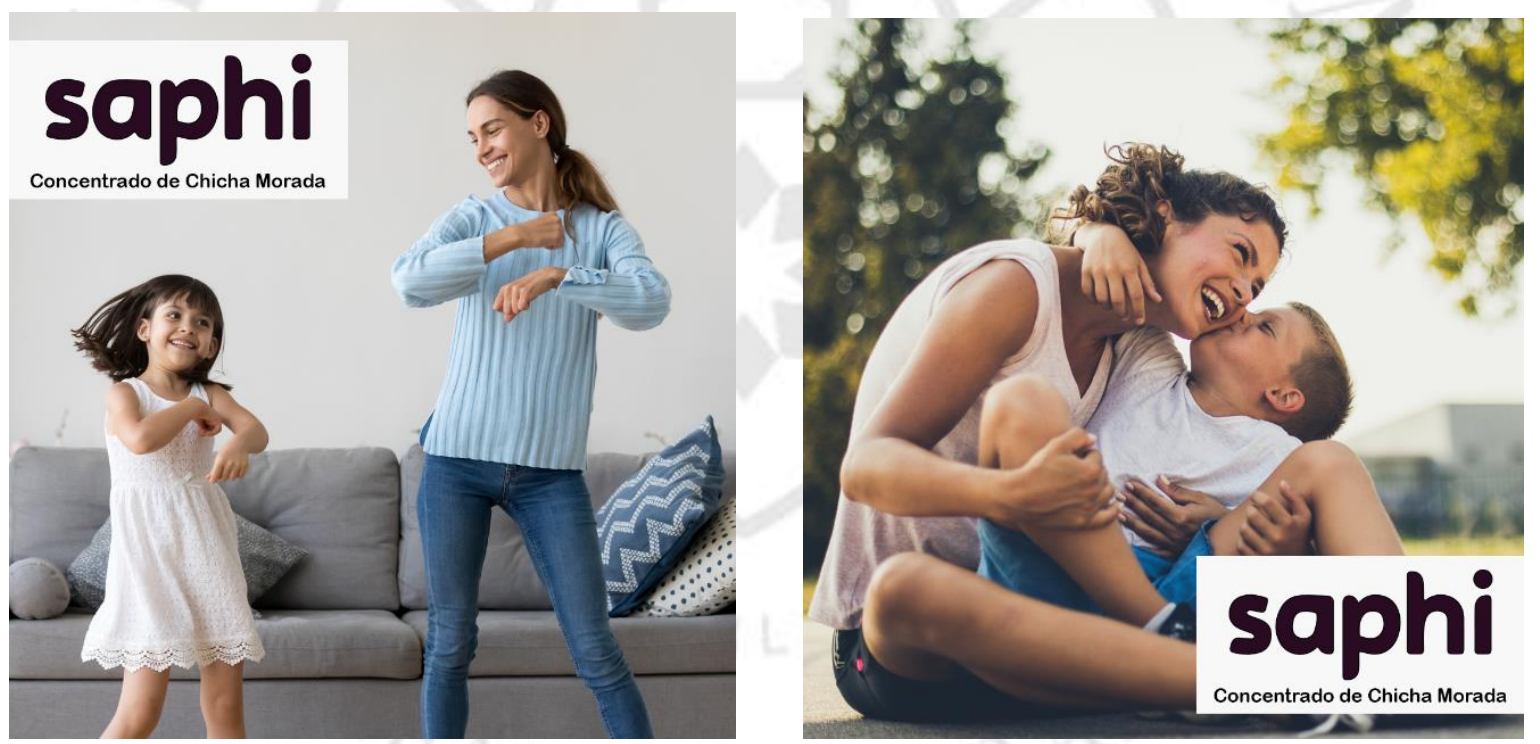


\section{- Display}

Se colocarán anuncios Display en YouTube con videos relacionados a música, alimentación, vida sana, trailers de películas, tips de belleza, recetas de cocina, entre otros. Las edades del público objetivo se mantienen.

Asimismo, los anuncios se colocarán en blogs con temáticas similares.

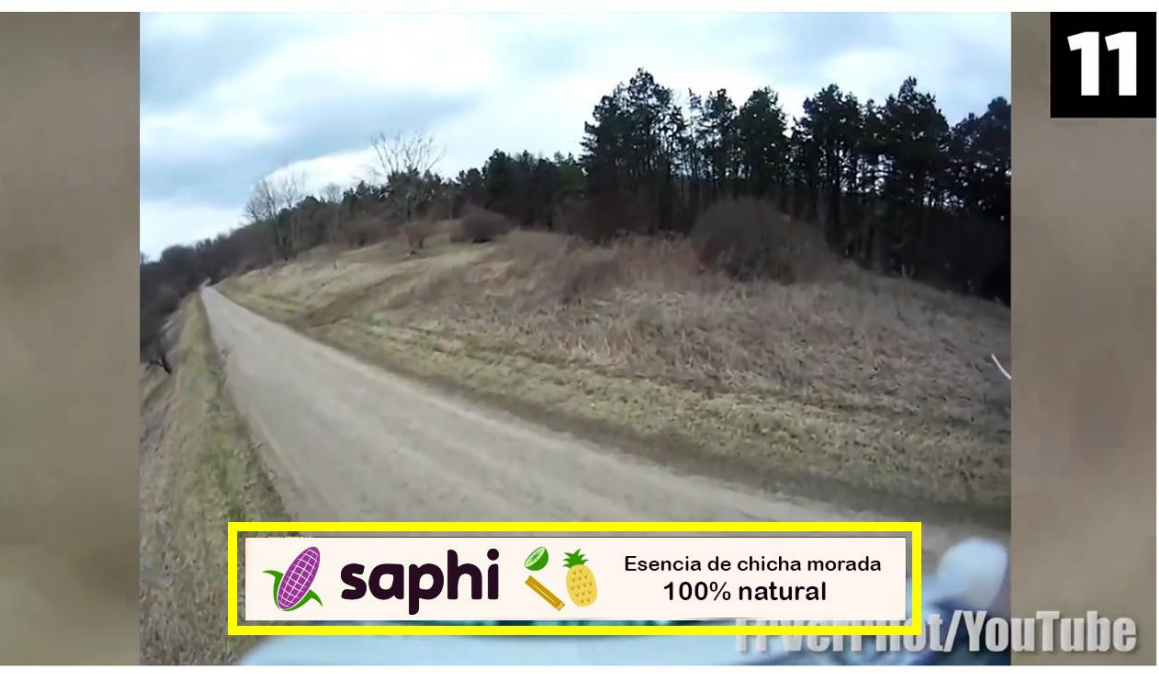

11 Scariest Things Caught By Drones $32,023,819$ views

Esencia de chicha morada

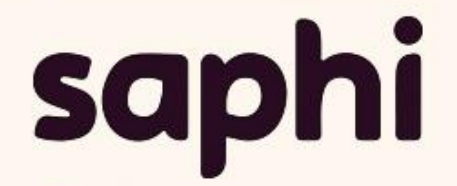

$100 \%$ natural

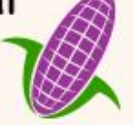

Up next

AUTOPLAY

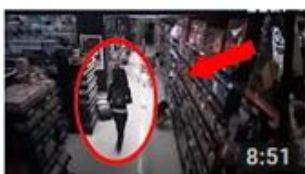

5 People With Superpowers

Caught On Tape

Terrifive 0

$50 \mathrm{M}$ views

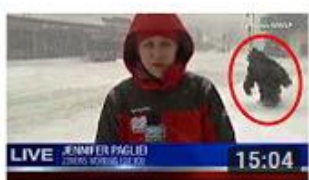

16 Mysterious Creatures

Caught on LIVE TV

chills 0

$13 \mathrm{M}$ views 


\section{CONCLUSIONES}

- Saphi quiere posicionarse como un producto con el verdadero sabor de chicha morada con ingredientes naturales y sin preservantes ni colorantes.

- El concepto de marca "El sabor natural de siempre" permite que el público objetivo asocie a este concentrado como un producto con el sabor original, con ingredientes naturales y hecho con la receta de siempre.

- La campaña tiene una duración de tres meses y se desarrollará de manera integral a través de medios digitales y no digitales.

- Se hará énfasis en la pauta digital a través de videos, comerciales en TV y paneles ubicados alrededor de los puntos de venta. 


\section{RECOMENDACIONES}

- A partir de las investigaciones de IPSOS y Arellano Marketing, las amas de casa, en especial las más jóvenes, tienen interés por las compras virtuales, por lo que el uso de aplicaciones como Glovo, Rappi y Uber Eats ayudarán a acercar a la marca a casa.

- La marca podría auspiciar eventos donde las familias sean las protagonistas, con juegos y comida peruana para que refuercen la sensación de que Saphi es la bebida que acompaña a las familias.

- En los meses julio y octubre, la marca puede aprovechar las festividades para promocionar el producto como la bebida tradicional del país.

- La marca debe seguir trabajando cómo las costumbres de las familias varían, pero el sabor tradicional de la chicha morada es el principal acompañante de cada comida. 


\section{REFERENCIAS}

Radio RPP (02 de mayo de 2019). Cinco de cada 10 hogares peruanos se consideran "saludable" o "muy saludable". Recuperado de https://rpp.pe/economia/economia/kantar-worldpanel-cinco-de-cada-10-hogaresperuanos-se-considera-saludable-o-muy-saludable-noticia-1182932

Kantar Worldpanel (2019). Hogares peruanos se orientan hacia consume saludable. Recuperado de https://www.kantarworldpanel.com/pe/Noticias/Hogares-peruanos-seorientan-hacia-consumo-saludable

Diario Gestión (06 de mayo de 2019). Naturale: "El consumo de bebidas saludables representa el $14 \%$ del mercado en Perú”. Recuperado de https://gestion.pe/economia/empresas/naturale-consumo-bebidas-saludables-representa14-mercado-peru-261846

Sitio web de Naturale (06 de mayo de 2019). Concentrado de chicha morada Naturale. Recuperado de http://www.naturale.com.pe/concentrado-de-chicha-moradabolsa/\#toggle-id-1

Sitio web de Corporación Merati (03 de mayo de 2019). Soy Fruta Concentrado de chicha morada. Recuperado de http://www.corporacionmerati.com/soy-fruta-concentrado-dechicha-morada.html

Sitio web de Compañía Nacional de Chocolates (02 de mayo de 2019). Productos de venta nacional. Recuperado de: http://www.chocolates.com.pe/es/productos/productosde-venta-nacional/bebidas/zuko

Sitio web de Alicorp (02 de mayo de 2019). Consumo masivo. Recuperado de http://www.alicorp.com.pe/alicorp/marcas/consumo-masivo/refrescos/negrita.html

IPSOS (2018). Perfil del ama de casa peruana.

IPSOS (2017). Medios tradicionales: Hábitos y actitudes. 
Arellano Marketing (03 de mayo de 2019). Los seis estilos de vida. Recuperado de https://www.arellano.pe/los-seis-estilos-de-vida/las-modernas/ 


\section{ANEXOS}

- Encuesta y resultados

Link con las imágenes: https://drive.google.com/drive/folders/1Xcy7ExQOA-

TKs8qh9ydW2pKPHyFsiTm-?usp=sharing

Se realizaron 100 encuestas a amas de casa de los NSE A, B y C entre las edades de 35 a 45 años. Los resultados son los siguientes:

¿Cuál es la característica que más destaca de la Chicha Morada?

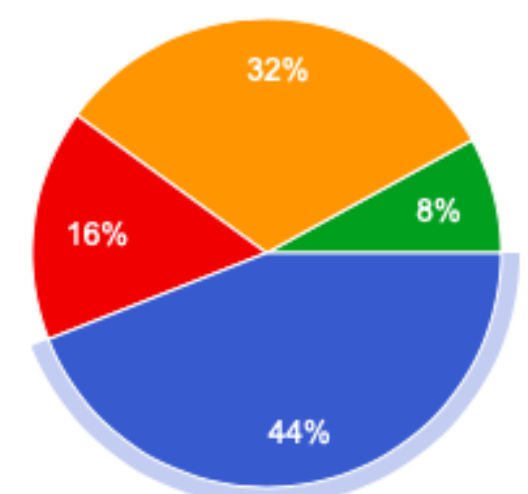

Sabor

Color

Ingredientes naturales

Beneficio nutricional

¿Con qué frecuencia consume Chicha Morada?

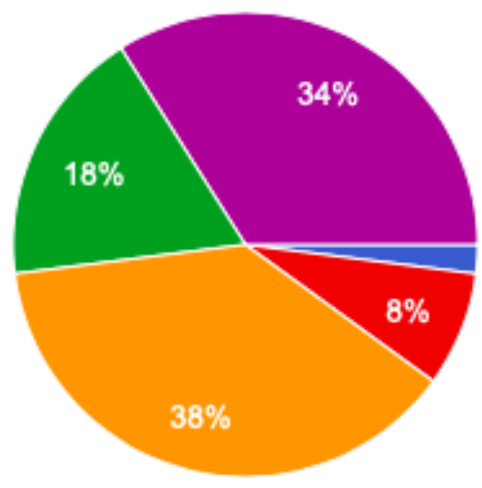

Todos los dias

203 veces por semana

1 vez por semana

- Cada quince dias

1 vez por mes 
¿En qué momento del día suele consumir Chicha Morada?

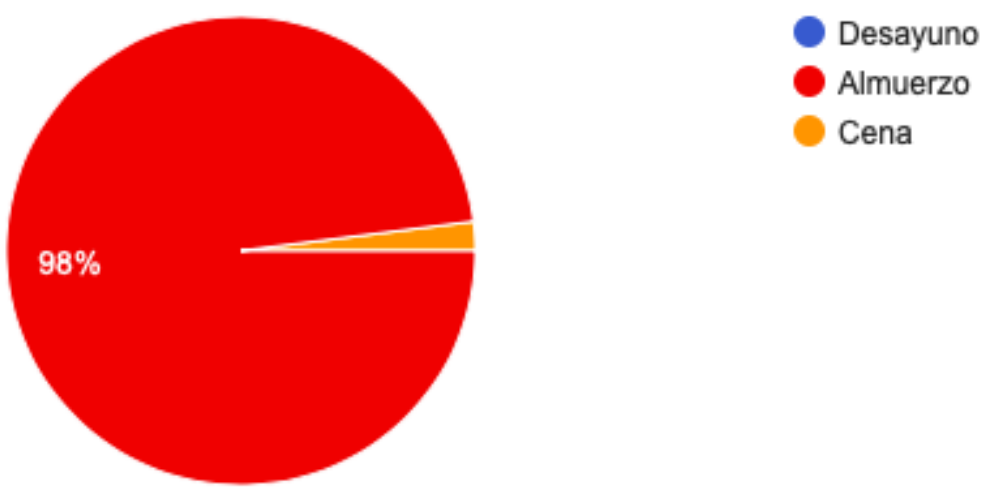

¿Cuál es el principal lugar donde consume Chicha Morada?

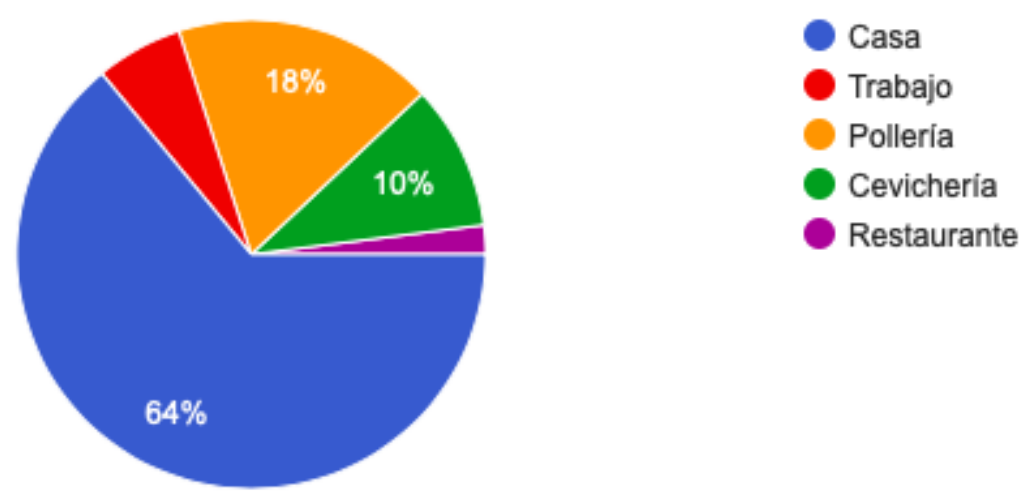


¿Cuál es el aspecto que menos le gusta de preparar Chicha Morada en casa?
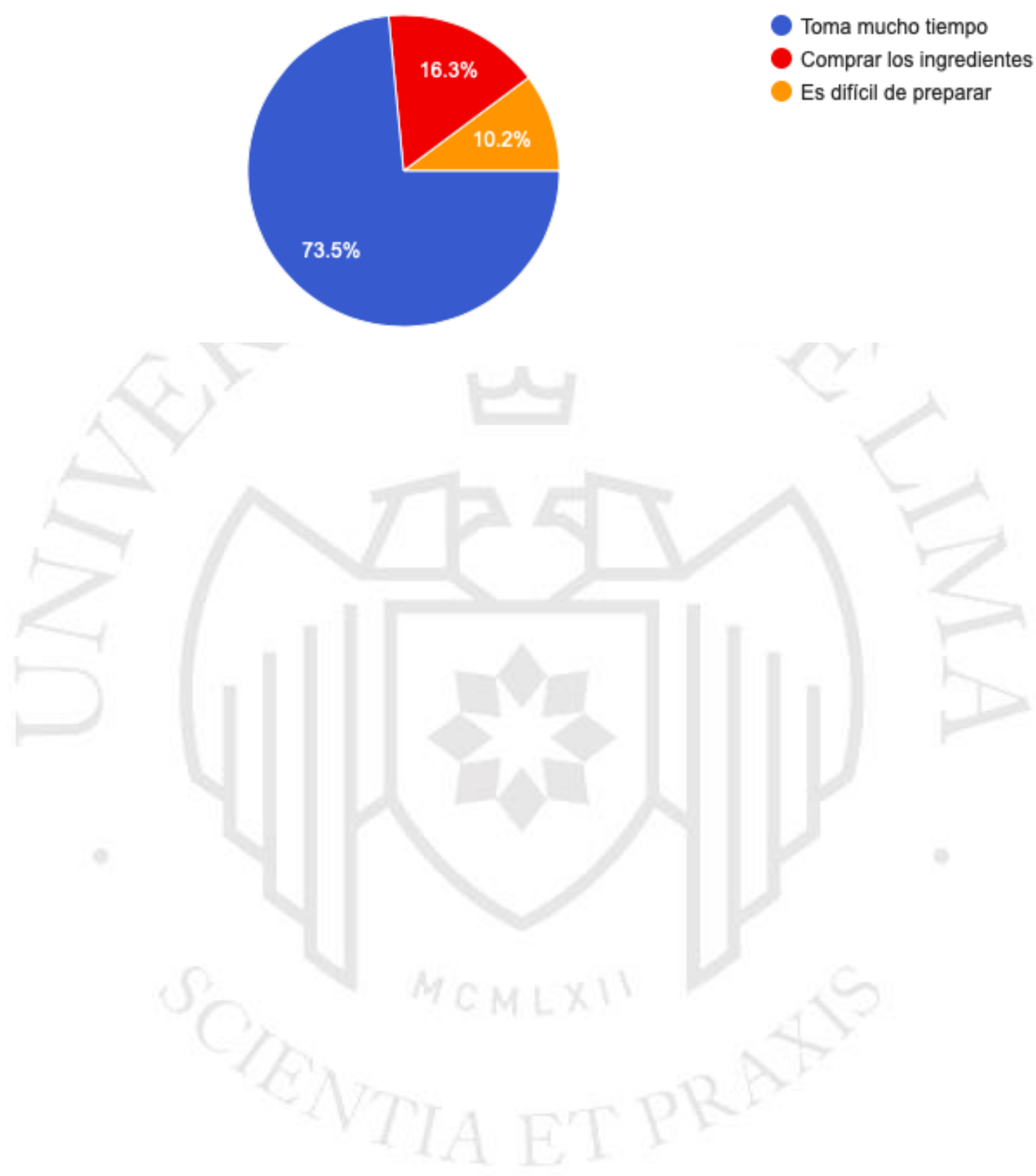